\title{
Além do arco-íris: uma reflexão sobre a trajetória do movimento gay
}

Beyond the rainbow: a reflection of the trajectory of the gay movement

\author{
RONALDO ADRIANO ALVES DOS SANTOS ${ }^{1}$
}

Resumo: A partir da discussão de três períodos históricos do movimento gay e de como ele e suas demandas se comportaram nesses diferentes momentos de sua história, este artigo objetiva discutir a trajetória do movimento desenvolvendo a hipótese de que ele atuou de forma revolucionária no interior do sistema capitalista, produzindo descodificações e desterritorializações, mas que de modo geral sucumbiu às investidas do sistema, sendo historicamente reterritorializado dentro da própria axiomática capitalista.

Palavras-chave: Movimento Gay. Descodificação. Reterritorialização.

Abstract: From the discussion of three historical periods of the gay movement and how it and its demands behaved in those different moments of its trajectory, this article aims to discuss the trajectory of this movement developing the hypothesis that it acted in a revolutionary way within the capitalist system, producing decodings and deterritorializations, but which generally succumbed to the onslaught of the system, being historically reterritorialized within the capitalist axiomatic itself.

Keywords: Gay Movement. Decoding. Reterritorialization.

\section{Tornado: o início de uma jornada}

\begin{abstract}
"Acho que escrever é um devir alguma coisa. Mas também não se escreve pelo simples ato de escrever. Acho que se escreve porque algo da vida passa em nós. Qualquer coisa. Escreve-se para a vida. É isso. Nós nos tornamos alguma coisa. Escrever é devir".
\end{abstract}

(Gilles Deleuze)

Como iniciar um texto? Quais palavras dizer? Por onde começar? Talvez a dificuldade de iniciar um texto decorra do fato de sabermos que esse é um caminho sem volta. Podemos apagar, reescrever e/ou começar novamente. Porém, jamais conseguimos retornar às nossas zonas de (des)conforto. $\mathrm{O}$ tornado nos arrebata. Se nos propomos a escrever o fazemos por experimentarmos o (des)prazer. Algo nos inquieta, nos arranca a tranquilidade, nos mobiliza, nos faz ir adiante. Assim o texto se configura como um território de lutas, confrontos e embates, mas também como canteiro de obras, de construção e produção. Ele é um lugar ambíguo tal qual a posição de autor. Nesse exercício de leitura e escrita destruímos crenças e ideias, muitas vezes arraigadas e preciosas para, a partir daí, construir novos caminhos,

\footnotetext{
${ }^{1}$ Mestrando em Psicologia e Sociedade pela Universidade Estadual Paulista "Júlio de Mesquita Filho" (UNESP) e Professor do Curso de Psicologia da Pontifícia Universidade Católica do Paraná (PUCPR). E-mail: ronaldo.alves@pucpr.br
} 
novas direções, novos devires. Abrimos espaços nos escombros para erigir novos fluxos de pensamento e criação.

É esse turbilhão de afetos (às vezes ambíguos, outras contraditórios) que nos acompanha na leitura que fazemos dos textos de Deleuze. Entretanto, esses afetos não foram e não são experimentados como uma força que desmobiliza ou paralisa, ao contrário, são fontes de potência e impulso para o pensar e o agir. Esses afetos tornam evidente que sair das nossas zonas de (des)conforto é um exercício constante, um processo difícil, duro, por vezes dolorido, mas necessário e não raras vezes prazeroso.

Mergulhados nesse processo afetivo e inquietante de leitura e escrita deparamonos com as reflexões de Deleuze sobre a sociedade capitalista, sua lógica estranguladora e a busca pelo estabelecimento de linhas de fuga dos tentáculos do capital.

[...] o sistema capitalista foge por todos os lados, ele foge, e depois o capitalismo colmata, faz nós, faz liames para impedir que as fugas sejam muito numerosas. Um escândalo aqui, uma fuga de capitais ali etc. E há também fugas de um outro tipo: há as comunidades, há os marginais, os delinqüentes, há os drogados, as fugas de drogados, há fugas de todo tipo, há fugas esquizofrênicas, há pessoas que fogem de maneira muito diferente (DELEUZE, 2004, p. 212).

É a partir desse reconhecimento da existência de diversas possibilidades de "fugas" que este texto objetiva discutir a trajetória do movimento gay ${ }^{2}$. Para tal, desenvolvemos a hipótese de que esse movimento atuou de forma revolucionária dentro sistema capitalista, produzindo descodificações e desterritorializações, mas que de modo geral sucumbiu às investidas do sistema, sendo historicamente reterritorializado na própria axiomática capitalista. Destarte, neste texto apresentaremos uma breve discussão sobre a história do movimento gay demonstrando como ele e suas demandas se comportaram em diferentes momentos de sua trajetória.

Ancoramos nossa discussão em três períodos históricos específicos do movimento gay, a saber: 1) a década de 1960 com a "revolução sexual"; 2 ) a década de 1980 com as demandas emancipatórias do movimento e as consequências da epidemia de AIDS; 3) a contemporaneidade com as reivindicações pelo casamento

\footnotetext{
${ }^{2}$ Optamos por discutir o movimento gay e não LGBTTT (Lésbicas, Gays, Bissexuais, Travestis, Transexuais e Transgêneros), pois reconhecemos as especificidades e as particularidades de cada um dos segmentos que compõe essa "supercategoria" (LGBTTT). Nesse sentido, compreendemos que as vivências, os desafios, as lutas, as reivindicações e as bandeiras levantadas por cada um deles operam de maneiras muito diversas e específicas não podendo, portanto, serem tratados de maneira homogênea. Além disso, reconhecemos que "o" movimento gay, em si, não existe, haja vista a diversidade de atores e de movimentos que compõe essa categoria genérica de análise. Adotamos neste texto essa categoria generalizante, advertidos desse problema e dos riscos em que ele incorre. Entretanto, assim procedemos para tornar viável a problematização que, por ora, almejamos desenvolver.
} 
civil igualitário. Ao abordarmos esses três períodos e eventos específicos não pretendemos restringir, minimizar ou totalizar a história do movimento gay, mas nossa intenção é produzir uma discussão que seja viável às dimensões de escrita aqui proposta.

\section{Na estrada de tijolos amarelos: alguns (des)caminhos do movimento gay}

A partir dessa compreensão inicial podemos afirmar que a ebulição de diferentes movimentos reivindicatórios que clamavam por maior liberdade sexual durante toda a década de 1960, processo que ficou conhecido como "revolução sexual”, produziu, sem sombra de dúvidas, reflexos tanto na produção acadêmica quanto nas relações sociais de forma mais ampla.

É nesse período de intensas reivindicações que podemos observar o florescimento do caráter revolucionário do movimento gay que conseguiu produzir um dos principais feitos de sua história, isto é, a garantia da despatologização das homossexualidades, que ocorre em 1973. Talvez esse tenha sido o principal processo de descodificação produzido pelo movimento, pois garante oficialmente a exclusão das homossexualidades do rol de doenças psiquiátricas inscritas no Manual Diagnóstico e Estatístico de Transtornos Mentais (Diagnostic and Statistical Manual of Mental Disorders - DSM).

Pensamos a conquista da despatologização das homossexualidades como um processo de descodificação não só pela sua retirada do DSM mas, principalmente, pelo fato dela consistir na refutação de toda a tradição patológica que pairava sobre essa população e que vigorou desde o século XIX (FOUCAULT, 2009). Ou seja, essa descodificação implica entender as homossexualidades, ao menos em termos estatísticos ${ }^{3}$, como um fenômeno normal.

Essa descodificação, que ocorre primeiro no meio acadêmico, produz ressonâncias na sociedade de forma mais ampla, abrindo brechas e ranhuras na estrutura social. Foram esses espaços que tornaram possível o início da construção de novas relações sociais, possibilitando, mesmo que não intensivamente, o espraiamento da compreensão sobre as homossexualidades e dos sujeitos por trás dos rótulos.

É importante ponderar que, embora as homossexualidades tenham deixado de ser compreendidas como patologia, os gays permaneceram sendo percebidos de maneira distinta em relação aos heterossexuais, sendo assim categorizados como indivíduos moralmente degenerados e inferiores. Inclusive nesse mesmo período as homossexualidades também permaneceram, literalmente, codificadas como crime. "O termo 'ofensor sexual', muitas vezes aplicado para estupradores, outras para

\footnotetext{
3 Falamos em termos estatísticos, pois a ideia de normalidade está associada a uma perspectiva probabilística que considera a frequência em que um dado evento ocorre em relação à população geral.
} 
'molestadores infantis', funcionou, eventualmente, como um código para homossexuais" (RUBIN, s/d, p. 4).

Foi justamente essa codificação que se tornou o centro das lutas do movimento gay na década de 1980. Encontrando inspiração nos movimentos feministas e étnicos da década de 1970, o movimento gay buscou uma nova descodificação, ou seja, modificar a percepção geral de que os homossexuais eram indivíduos criminosos, exóticos e que se distinguiam do heterossexual, esse último compreendido como um indivíduo normal e respeitável. O movimento buscava, assim, a descriminalização das homossexualidades. A estratégia utilizada pelo movimento foi "recuperar uma subjetividade gay ou lésbica que havia sido historicamente negada" (GAMSON, 2006, p.349). Essa proposta descodificante se alinhava com uma série de lutas emancipatórias que marcam a década de 1980 e se caracterizava pelo início da luta por direitos civis à população homossexual, e pela tentativa de construir uma compreensão das homossexualidades como uma variação normal da sexualidade (SAMPAIO; GERMANO, 2014).

É também na década de 1980 que vivemos o surto de HIV/AIDS e, graças a esse evento, ligado a uma série de outros fatores sociais relacionados à compreensão das homossexualidades, assistimos a um processo de recodificação e reterritorialziação da população homossexual. Sabemos que a AIDS foi inicialmente nomeada como GRI (Imunodeficiência Gay Adquirida), pois acreditava-se que era ela uma "doença gay". Alguns estudos apontavam que a cada cinco infectados dois mantinham relações homossexuais frequentes (PELÚCIO; MISKOLCI, 2009). Mesmo depois da síndrome ter sido renomeada como AIDS (Síndrome da Imunodeficiência Adquirida), restou no campo da fantasia uma relação direta entre as homossexualidades e a doença, o que resultou na repatologização dos homossexuais.

Se antes as homossexuliadades eram consideradas como um problema de saúde mental, a partir desse momento elas se tornaram uma questão epidemiológica, sendo muito mais assombrosa à sociedade, o que contribuiu para que essa população fosse vista como um perigo à saúde pública e que, a partir de então, “[...] passassem por um processo de politização controlada" (MISKOLCI, 2011, p. 49). Nesse sentido, e considerando a luta travada contra a epidemia de AIDS, foram produzidas uma série de ações endereçadas à população afetada pelo vírus e também para possíveis vítimas, entre as quais destacavam-se os homossexuais.

O conjunto de ações que foram engendradas nesse período favoreceu a expansão do movimento gay e o surgimento de uma série de organizações, associações e grupos gays financiados por programas governamentais e instituições internacionais. É importante ponderar, porém, que, se de um lado, essas "alianças" entre o movimento gay, organismos institucionais e estatais resultou numa maior visibilidade e debate sobre as homossexualidades em diferentes espaços da sociedade (SAMPAIO; GERMANO, 2014), por outro lado, serviu para o início de um processo de 
reterritorialização do movimento gay. Tal processo reinseriu o movimento na axiomática do capitalismo, fagocitando o movimento molecular em prol dos interesses molares $^{4}$, pois o financiamento tanto governamental quanto de organismos internacionais servem de maneira implícita ou explícita para direcionar e controlar as lutas e reivindicações do movimento via capital investido.

Foram esses espaços e "alianças", forjados via investimentos de capital, que resultaram numa nova onda de reivindicações do movimento gay com a proposição de projetos de lei não mais circunscritos apenas à saúde e ao combate à AIDS, mas também ligados à educação, cultura, trabalho, direitos humanos e outros (MISKOLCI, 2011). E é no bojo dessas demandas que se levanta a bandeira do "casamento civil igualitário" popularmente conhecido como "casamento gay".

Se compreendermos o casamento como a celebração contratual que une civilmente duas pessoas e que, portanto, exige o reconhecimento estatal dessa união, somos levados à conclusão de que em um Estado Democrático de Direito a instituição do casamento não poderia ser condicionada à orientação sexual dos contratantes. Entretanto, é de conhecimento geral os obstáculos encontrados pela população LGBTTT em acessar tal dispositivo jurídico. E bem de encontro a estes obstáculos é que se localiza a demanda pelo "casamento civil igualitário".

Embora consideramos o acesso igualitário aos direitos civis, entre os quais inclui-se o casamento, como uma luta absolutamente necessária para o alcance da democracia, não podemos deixar de notar o quanto essa reivindicação tem servido para reterriotorializar o movimento gay, sedimentando seu serviço à axiomática capitalista, pois a população gay não é percebida em suas demandas reais. Assim, ela tem sido compreendida e encarada como um nicho de mercado, mais um locus produtor de consumidores e que precisa ser colonizado.

Nessa perspectiva é perceptível o aumento de campanhas publicitárias e produções midiáticas de grandes veículos de comunicação que abordam a comunidade e os relacionamentos gays apresentando e representando a vida e as relações desta população de forma romanceada e asséptica. E nesse processo, aquela demanda que surge como necessidade de gozo igualitário de direitos se converte pela

\footnotetext{
${ }^{4}$ Deleuze $(1995 ; 1996)$ propõe uma discussão que nos permite pensar a sociedade como um constructo atravessado por dois planos políticos distintos: o macropolítico molar e o micropolítico molecular. Segundo Guattari e Rolnik (2005, p. 386), "a ordem molar corresponde às estratificações que delimitam objetos, sujeitos, representações e seus sistemas de referência. A ordem molecular, ao contrário, é a dos fluxos, dos devires, das transições de fases, das intensidades". Segundo Alvim (2012p. 306) "são dois sistemas de referência que estão em razão inversa: enquanto um escapa, o outro detém, enquanto um deserta, o outro impede a continuidade da fuga. Existe complementaridade e coexistência entre os dois planos, mas é preciso notar que o nível molar somente detém o molecular em um plano, que é o seu próprio. Ou seja, o sistema duro não abole a vivacidade dos fluxos, que continua perpetuamente mutante [...] - de tal modo que - o nível molecular pode ser envolvido e canalizado pela esfera molar, mas é também possível que ele rompa os diques e imponha uma reestruturação geral das organizações molares".
} 
lógica estranguladora do capital em um pedido de participação, de ingresso no "clube" que, anteriormente, rechaçava toda essa população.

Não deixa de chamar a atenção que esse processo tem sido conduzido à sombra da heteronormatividade e de uma perspectiva familista. Compreendemos ambas como produtos do dispositivo ${ }^{5}$ da sexualidade que elege a heterossexualidade como fundamento da sociedade, tomando assim a heterossexualidade como performance sexual compulsória. Essa produção histórica e social induz, não raras vezes, homens e mulheres homossexuais a aspirar e performatizar comportamentos que mimetizam a heterossexualidade como ticket normatizado de ingresso e participação social.

Por conseguinte, e tomando a heterossexualidade como norma a própria perspectiva familista, compreende-se a família como instituição monolítica formada por um casal heterossexual e sua prole. Essa perspectiva é fortemente reforçada pelas construções psicanalíticas que compreende a constituição do inconsciente, ou seja, a estruturação do sujeito, a partir da triangulação edípica papai, mamãe e filhinho, ou seja, uma compreensão que aprisiona o sujeito na novela familiar ao invés de perceber a configuração inconsciente como uma produção que deriva do campo social. Conforme nos explicam Deleuze e Guattari:

Aí está o incurável familismo da psicanálise, enquadrando o inconsciente em Édipo, atando-o de um lado e de outro, esmagando a produção desejante, condicionando o paciente a responder papaimamãe e a consumir sempre papai-mamãe (DELEUZE; GUATTARI, 2010, p. 128).

Nesse mix heteronormativo e familista é comum, até corriqueiro, ouvirmos expressões como, por exemplo, enunciados do tipo: "nem parece gay", "sem problemas ser gay, só não precisa 'dar pinta”; "tudo bem ser gay, mas se dê ao respeito"; "é gay, mas estão juntos há anos, estão casados"; "vocês pensam em adotar quando?”. Essas e tantas outras expressões trazem, de forma mais ou menos explícita, um ideário em torno daquilo que vêm a ser uma sexualidade normal e/ou aceitável e daquilo que pode ou não ser considerado família.

Temos percebido que a adesão a esse tipo de discurso tem se tornando cada vez mais comum. Assim, não podemos deixar de analisar esse movimento como resultado de um processo de recodificação e reterriorialização das homossexualiades, processo esse que desmobiliza e fragiliza o devir revolucionário do movimento gay, colocandoo a serviço da lógica molar da sociedade capitalista. Confirmando o movimento já analisado por Deleuze quando este autor afirma que o capitalismo é “[...] um sistema

\footnotetext{
5 Foucault (200o, p. 244) conceitua o dispositivo como "um conjunto decididamente heterogêneo que engloba discursos, instituições, organizações arquitetônicas, decisões regulamentares, leis, medidas administrativas, enunciados científicos, proposições filosóficas, morais, filantrópicas. Em suma, o dito e o não dito são os elementos do dispositivo. O dispositivo é a rede que se pode tecer entre estes elementos".
} 
que foge realmente por todos os lados e que, ao mesmo tempo, não pára de impedir, de reprimir ou de colmatar as fugas por todos os meios" (DELEUZE, 2004, p. 212).

\section{O voo dos sapatos encantados: os últimos passos}

A partir dessa (re)construção da trajetória do movimento gay, pudemos perceber que ele possui potências para servir como um mecanismo da "máquina de guerra" revolucionária (DELEUZE, 2004) no processo de “desfamiliarização" e "desedipianização" das relações sociais, lutando pela ampliação da compreensão de família para além da triangulação casal mais filhos. Porém, em seu processo histórico e principalmente na atualidade tem buscado inserir-se nessa geometria familiar, servindo assim à manutenção da lógica familista e do controle das máquinas desejantes através do dispositivo jurídico do casamento. Essa demanda que agora ocupa, em grande medida, a agenda do movimento gay é fruto de um processo histórico tanto deste movimento quanto da própria sociedade capitalista e vai ao encontro do problema apresentado por Deleuze (2004).

Nosso problema (nós não somos completamente estúpidos, não dizemos que isso será suficiente para fazer a revolução) é: dado um sistema que foge realmente por todos os lados e que, ao mesmo tempo, não pára de impedir, de reprimir ou de colmatar as fugas por todos os meios, como fazer para que essas fugas não sejam simplesmente tentativas individuais ou pequenas comunidades, mas que elas formem verdadeiramente máquinas revolucionárias? E por que razão, até o presente, as revoluções foram tão mal? Não há revolução sem uma máquina de guerra central, centralizadora. Não se luta, não se duela a socos, é preciso uma máquina de guerra que organize e unifique. Mas, até o presente, não existiu no campo revolucionário uma máquina que não reproduzisse, a seu modo, uma outra coisa, ou seja, um aparelho de Estado, o organismo mesmo da opressão. Eis o problema da revolução: como uma máquina de guerra poderia dar conta de todas as fugas que se fazem no sistema sem esmagá-las, liquidá-las, e sem reproduzir um aparelho de Estado? (DELEUZE, 2004, p. 212-213).

Desse modo, percebemos que a luta pelo casamento civil igualitário acaba por reproduzir justamente mecanismos do aparelho estatal e assim se caracteriza pelo fato das demandas do movimento, por mais específicas que sejam, terem se restringindo apenas à "comunidade gay" obstacularizando a luta coletiva contra a perspectiva familista reinante em nossa sociedade.

Assim, não nos resta dúvida que, embora tenhamos assistido de diferentes formas a reterritorialização e recodificação de diversos movimentos sociais (a exemplo do movimento gay), a resposta ao problema apresentado por Deleuze só poderá ser produzida por um processo de luta coletiva que, nas palavras do autor, “[...] comporte um mínimo de desordem, mesmo que seja apenas uma esperança revolucionária, um grão de revolução permanente” (DELEUZE, 2004, p.93). 
SANTOS, R.

\section{Referências}

ALVIM, D. M. "A megamáquina política: poder, resistência e deserção". In: Kínesis, Vol. 4, n. 7, Julho de 2012. p. 303-319. Disponível em:

http://www2.marilia.unesp.br/revistas/index.php/kinesis/article/view/4472. Acesso em: 20 jul. 2016.

DELEUZE, G. Ilha deserta. São Paulo: Editora Iluminuras, 2004. Mil platôs: capitalismo e esquizofrenia, v.1. São Paulo: Ed. 34, 1995. Mil Platôs: capitalismo e esquizofrenia, vol. 3. Rio de Janeiro: Ed. 34, 1996.

DELEUZE, G; GUATTARI, F. O anti-Édipo: capitalismo e esquizofrenia. Tradução de Luiz B. L. Orlandi. São Paulo: Ed. 34, 2010. 560 p.

FOUCAULT, M. História da sexualidade I: a vontade de saber. (M. T. C. ALBUQUERQUE \& J. A. G. ALBUQUERQUE Trads. 19a. ed.) Rio de Janeiro: Graal, 2009.

. Sobre a História da sexualidade. In: . Microfísica do poder. Rio de Janeiro: Graal, 200o. p. 243 - 27.

Guattari, F.. Rolnik, S. Micropolítica: cartografias do desejo. Petrópolis, RJ: Vozes, 2005 .

GAMSON, J. "As sexualidades, a teoria queer e a pesquisa qualitativa”. In N. K. Denzin \& Y. S. Lincoln. O planejamento da pesquisa qualitativa: teorias e abordagens. (pp. 345-362). Porto Alegre: Artmed/Bookman, 2006.

MISKOLCI, R. "Não ao sexo rei: da estética da existência foucaultiana à política queer”. In L. SOUSA, T. SABATINE, \& B. MAGALHÃES (Orgs.). Michel Foucault: sexualidade, corpo e direito. (pp. 47 -68). Marília: Oficina Universitária; São Paulo: Cultura Acadêmica, 2011.

PELÚCIO, L. \& MISKOLCI, R. A prevenção do desvio: o dispositivo da AIDS e a repatologização das sexualidades dissidentes. Sexualidad, Salud y Sociedad: Revista Latinoamericana. 1, 125-157, 2009.

RUBIN, G. Pensando sobre sexo: notas para uma teoria radical da política da sexualidade. Disponível em:

https://repositorio.ufsc.br/bitstream/handle/123456789/1229/rubin_pensando_o_sexo.pdf?sequence $=1$. Acesso em: 13 mar. 2017.

SAMPAIO, J. V; GERMANO, I. M. P. Políticas públicas e crítica queer: algumas questões sobre identidade LGBT. Psicol. Soc., Belo Horizonte, v. 26, n. 2, p. 290-300, ago. 2014. Disponível em http://www.scielo.br/scielo.php?script=sci_arttext\&pid=So10271822014000200006\&lng=pt\&nrm=iso. Acesso em: 20 jul. 2016.

Submissão: 04.05.2017 / Aceite: 02.06.2017 